Goldschmidt 2021 Abstract

https://doi.org/10.7185/gold2021.5373 diverse archaeal community thriving in the hydrocarbon-rich environments of the Pescadero Basin.

\section{Characterization of the archaeal communities involved in methane and hydrocarbon oxidation within hydrothermal environments of the $S$. Pescadero Basin (Gulf of California).}

\author{
RAFAEL LASO PEREZ ${ }^{1,2}$, ANTOINE CRÉMIÈRE ${ }^{3}$, FABAI \\ $\mathrm{WU}^{3}$, DAAN R. SPETH ${ }^{3}$, FLORENCE SCHUBOTZ ${ }^{1}$, JOHN \\ MAGYAR $^{3}$ AND VICTORIA ORPHAN ${ }^{1,3}$ \\ ${ }^{1}$ MARUM - Zentrum für Marine Umweltwissenschaften der \\ Universität Bremen \\ ${ }^{2}$ Max Planck Institute for Marine Microbiology \\ ${ }^{3}$ Caltech
}

Presenting Author: rlperez@mpi-bremen.de

The Southern Pescadero Basin is a recently discovered hydrothermal vent area located at the southern mouth of the Gulf of California at a depth of $3650 \mathrm{~m}$. Here, vent fluids enriched in oil and gases migrate from the seafloor and support distinct microbial communities within anoxic sediments and hydrothermally-precipitated minerals, usually coupled to sulfate reduction. Using a combination of environmental metagenomics, laboratory microcosm experiments, geochemical and mineralogical analyses, we characterized the diversity and metabolism of archaea involved in methane and hydrocarbon oxidation, with a focus on the diverse members of the ANME-1 order, which are the most abundant anaerobic methane oxidizers in both habitats. Our working hypothesis within the Pescadero vent ecosystem is that different substrate habitats (e.g. mineral rocks vs. sediments) support distinct ANME-1 clades with diverse metabolic capabilities. Hydrothermal sediment cores and rock samples were collected from the Auka vent field. Sediment cores were collected within grey-orange mats, supported by the highly reducing sulfidic sediments near the seabed. Mineralogical analysis of the rock samples revealed they were predominately comprised of barite, with some of them impregnated with oil. We performed metagenomic analysis on four rocks and two sediment samples and reconstructed metagenome-assembled genomes (MAGs) affiliated with ANME-1. Two dominant ANME-1 groups were present in our sample set. Rock samples were dominated by a deep-branching ANME-1 clade, while sediments had a higher relative abundance of ANME-1a archaea. Comparative metagenomic analysis revealed differences in the potential metabolism between these lineages. Notably, the rock-associated ANME-1 genomes encode for a hydrogenase, a rare feature within ANME-1 that could be related to the syntrophic coupling with their sulfate-reducing partner bacteria or perhaps suggestive of methanogenic metabolism by members of the deep branching ANME-1. In addition, we recovered a MAG of the archaeal alkane oxidizer ' $\mathrm{Ca}$. Syntrophoarchaeum' from one of the oil-saturated rocks. In microcosm experiments with some of the rocks, sulfate reduction exceeded methane oxidation rates, indicating that a fraction of the sulfate reduction was likely coupled to the oxidation of higher hydrocarbons. Our analyses demonstrate the presence of a 